\title{
Antimicrobial, Antioxidant, and Dye Degradation Properties of Biosynthesized Silver Nanoparticles From
} Artemisia Annua L.

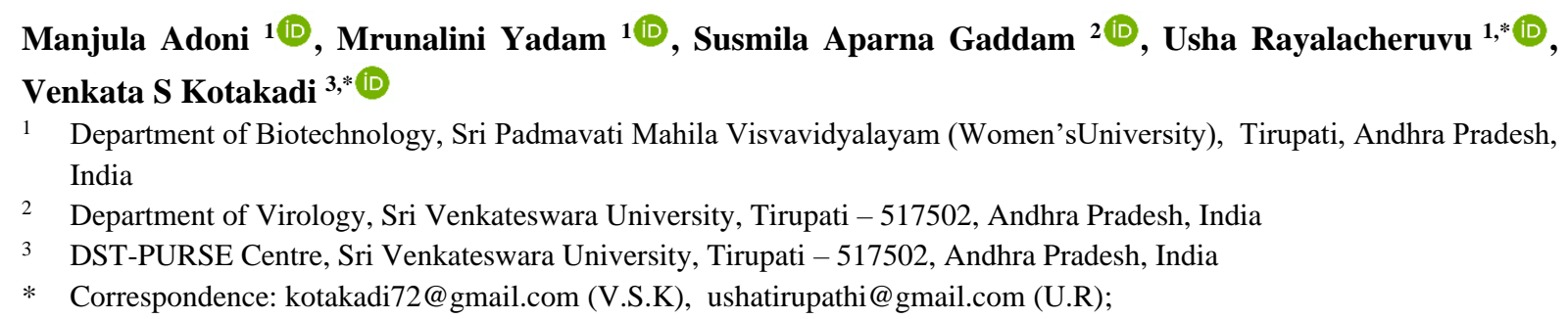

Received: 17.06.2020; Revised: 20.09.2020; Accepted: 28.09.2020; Published: 4.10.2020

\begin{abstract}
The biosynthesis of metallic nanoparticles with plant extract is a promising alternative method to traditional chemical methods. Artemisia annиa $\mathrm{L}$ is a well-known Chinese herb for its potent therapeutic anti-malarial activity and antitumor effects. Artemisinin, a sesquiterpene lactone derived from Artemisia annua L. Although artemisinin's anticancer effect has been extensively reported, the precise mechanisms underlying its cytotoxicity remain under intensive study. In the present work rapid and simple method for green synthesis of silver nanoparticles with the leaf extract of the therapeutic plant Artemisia аппиа L.was carried-out. The biologically synthesized silver nanoparticles were analyzed using spectroscopic methods like UV-visible spectroscopy. Fourier transforms infrared spectroscopy (FT-IR), Zeta potential, and particle size. The green Aa-AgNPs are characterized by spectral analysis by Nanodrop-UV-visible spectroscopy. The surface Plasmon resonance peak of silver nanoparticles in colloidal solution showed maximum absorption $441 \mathrm{~nm}$. FT-IR spectroscopy results indicate the $\mathrm{O}-\mathrm{H}$ phenolic group's participation, $\mathrm{C}=\mathrm{C}$ aromatic stretching, $\mathrm{N}-\mathrm{H}$ secondary amide stretching, and C-H methylene group stretching. Dynamic light scattering measurements of Aa-AgNPs revealed that the particle size is between $5-20 \mathrm{~nm}$. The zeta potential of the green synthesized AaAgNPs was found to be $-26.1 \mathrm{mV}$. The high negative potential indicates long-term stability. The antioxidant activity of Aa-AgNPs was evaluated by DPPH assay. The results revealed that they have very good antioxidant activity, which can be useful as a potential free radical scavenger. The biosynthesized Aa-AgNPs of Artemisia annua exhibited good antimicrobial activity. The Aa-AgNPs showed excellent catalytic activity in the reduction of lemon yellow and orange-red food dyes. The AaAgNPs can also act as an effective seed germination agent. Hence it is concluded that the green AaAgNPs can be useful for various biomedical and industrial applications.
\end{abstract}

Keywords: Biosynthesis; Artemisia annua L; Antimicrobial; Antioxidant; Dye Degradation.

(C) 2020 by the authors. This article is an open-access article distributed under the terms and conditions of the Creative Commons Attribution (CC BY) license (https://creativecommons.org/licenses/by/4.0/).

\section{Introduction}

For the past several years, the development of a new procedure for the biosynthesis of different types of nanoparticles with the required size and shape has been an interesting research area for scientists working in nanotechnology and biotechnology [1-2]. Research on Nanomaterials is an upcoming and promising area in medicine and other biomedical applications, and the biosynthesis of metallic NPs for other medicinal applications is an 
interesting area of existing research [3]. Among different metal nanoparticles, silver nanoparticles (AgNPs) fascinated various researchers due to their outstanding applications in diverse research fields like biosensors and biomedicine, catalysis, photonics, and pharmaceuticals. AgNPs are widely used as anti-angiogenic,[4] antimicrobial [5] and anticancer agents. It is well known that different chemical and physical methods are widely used for the green synthesis of AgNPs [6], such as chemical reduction[7], photochemical reduction [8], electro-irradiation [9], ultraviolet (UV) irradiation [10], microware irradiation [11] and laser-mediated synthesis[12]. Presently the green synthesis of AgNPs by different plants like Andrographis paniculata, Cathranthus roseus, Ficus fruit, Coleus aromaticus leaf, Glycorhiza galbra root, Cassia alata leaf [13-18], Scytonema geitleri, Glycosmis pentaphylla plants, probiotic bacteria and also by using algae and microalgae [19-22] have proven to be a simple, stable and inexpensive viable alternative method to chemical and physical methods. They have been widely used to synthesize metallic nanoparticles and study their spectral and biomedical properties.

Artemisia is a large and diverse genus of plants with approximately 400 species belonging to the Asteraceae family. Some species of the genus have been used as food additives [23], anti-malarial, anti-hepatotoxic [24-25], anti-inflammatory [26], antimicrobial and antiviral agents [27-29]. Several Artemisia species have medicinal properties that are widely used to treat various diseases such as invigorating blood, relieving cough, stopping pain, as a diuretic, anthelminthic, antiallergenic, and antitoxic agents [30]. Artemisia species are distributed extensively in Asia, Europe, and other parts of North America. More than 150 species of Artemisia flora were of Asian origin. Most of them distributed in states of the Chinese Republic, 34 reported species of this genus in Iran. Two of these species are endemic [31-32].

The different organic compounds present in A.annua plant extract include many essential oils, terpenoids, and flavonoids. The phyto-bioactive constituents present in the aqueous extract of A.апnиа play an important role in reducing, capping, and stabilizing the biosynthesized Ag+ ions. Though there are several studies on green synthesis, we hereby report a rapid and straightforward method for the biosynthesis of Aa-AgNPs using leaf extract of Artemisia annua and studied their therapeutic applications. The biosynthesized Aa-AgNPs were evaluated by a range of spectral methods. They evaluated their antibacterial, free radical scavenging activity, dye degradation and seed germination.

\section{Materials and Methods}

\subsection{Plant material.}

The leaves of Artemisia annua were collected from the CIMAP (Central Institute of the Medicinal and Aromatic Plants), Lucknow, India. The selected parts of A. апnиa plants were then dried in the shade at room temperature ground into powder. $20 \mathrm{~g}$ of powder was added to $200 \mathrm{~mL}$ of distilled water. The mixtures were boiled at $70^{\circ} \mathrm{C}$ for 30 minutes, allowed to cool to room temperature, and filtered through cheesecloth followed by Whatman filter paper.

\subsection{Synthesis of silver nanoparticles.}

The freshly prepared aqueous extract was used immediately after filtration. An aqueous solution of $\mathrm{AgNO}_{3}(0.1 \mathrm{mM})$ and $(0.2 \mathrm{mM})$ was prepared and used for the biosynthesis of AgNPs. Two test tubes were taken, and $1 \mathrm{~mL}$ of aqueous extract of Artemisia annua was added 
to each test tube. Then $4 \mathrm{~mL}$ of distilled water was added to each test tube. $10 \mathrm{~mL}$ of $0.1 \mathrm{mM}$ aqueous solution of silver nitrate in one test-tube and $10 \mathrm{ml}$ of $0.2 \mathrm{mM}$ aqueous solution of silver nitrate solution into another test tube were added, mixed thoroughly, and incubated. After incubation, development of reddish-brown color was observed and therefore indicated the formation of green silver NPs. These particles were stored at $4^{\circ} \mathrm{C}$ till further use.

\subsection{Spectral characterization of silver nanoparticles.}

\subsubsection{UV-Visible spectrophotometer.}

The bio-reduced AgNPs are analyzed by using a UV-visible spectrophotometer Nanodrop-8000 (Thermo Scientific, USA) within the wavelength range of $220 \mathrm{~nm}-750 \mathrm{~nm}$.

\subsubsection{Fourier transform infrared spectroscopy (FT-IR).}

FT-IR analysis was used to recognize the different functional groups of phytoactive biomolecules of Artemisia annua involved in the reduction of silver nitrate to AgNPs. The obtained Aa-AgNPs were analyzed by FT-IR spectroscopy. FTIR measurements were carried out from $4000 \mathrm{~cm}^{-1}$ to $400 \mathrm{~cm}^{-1}$ on a Perkin Elmer spectrometer in diffuse reflectance mode at a resolution of $4 \mathrm{~cm}^{-1}$ using $\mathrm{KBr}$ pellets.

\subsubsection{Particle size and zeta potential.}

The particle size and zeta potential analysis were carried out by using Nanopartica SZ100, Horiba Nanoparticle analyzer, DST PURSE center, Sri Venkateswara University, Tirupati. The size was calculated based on the Brownian motion of the nanoparticles suspended in a colloidal solution of Aa-AgNPs were measured using DLS. The zeta potential analysis was carried out to determine the surface charge of the biosynthesized Aa-AgNPs, which is very much useful to assess the stability.

\subsection{Antibacterial activity.}

\subsubsection{Bacterial strains.}

Escherichia coli, Bacillus subtilis, staphylococcus aureus, klebsiella pneumonia were obtained from DST PURSE center, S.V. University. The strains were maintained on agar slant at $4{ }^{\circ} \mathrm{C}$ and activated at $37^{\circ} \mathrm{C}$ for $24 \mathrm{~h}$ on nutrient agar (Sigma-Aldrich, Germany).

\subsubsection{Evaluation of antibacterial activity.}

The antibacterial activity of biosynthesized Aa-AgNPs was performed by disc diffusion method. The nutrient agar plates were inoculated with $200 \mu \mathrm{L}$ of overnight cultures of Grampositive and Gram-negative bacterial strains by the spread-plate method. On the inoculated nutrient agar plates, $5 \mathrm{~mm}$ diameter filter paper disc placed and were impregnated with different concentrations of test extracts $(10,20,30$, and $50 \mu \mathrm{L})$. The agar plates were incubated overnight at $37^{\circ} \mathrm{C}$. The zone of inhibition (ZOI) was measured by using a transparent scale. Levofloxacin $(30 \mu \mathrm{g} /$ disc) was used as a positive control. 


\subsection{Antioxidant activity.}

Diphenyl-1-picryl hydrazyl radical scavenging assay (DPPH): The antioxidant activity of Aa-AgNPs was performed by using 2,2-diphenyl-1-picryl hydrazyl (DPPH) assay. Different concentrations $(100-500 \mu \mathrm{g} / \mathrm{mL})$ of biosynthesized Aa-AgNPs and the standard positive control Ascorbic acid were taken separately in different sterile $10 \mathrm{ml}$ test tubes $3 \mathrm{~mL}$ DPPH solution was added to final concentration $0.1 \mathrm{mM}$. The reaction solutions were mixed thoroughly, and the reaction was carried in dark condition at room temperature for $\sim 30$ minutes. After 30 minutes, the free radical scavenging activity Aa-AgNPs was analyzed using a UV 1601 UV-visible spectrophotometer (Shimadzu Corporation, Japan) at $517 \mathrm{~nm}$. The DPPH solution without any sample is considered as a control. Finally, the percentage of antioxidant activity was calculated by the following equation:

$$
\text { Inhibition } \%=1-(\mathrm{A} \text { sample } / \mathrm{A} \text { blank }) \times 100
$$

Asample: Absorbance of the sample, Ablank: Absorbance of the DPPH

\subsection{Dye degradation.}

Two food dyes were used to test the degradation capacity of synthesized silver nanoparticles. Lemon yellow and orange-red dyes were taken. 100mg of each dye was dissolved in $50 \mathrm{ml}$ of distilled water. This was left overnight for dispersion. The next day, UV spectrophotometer readings were taken for both the dyes. Then $5 \mathrm{ml}$ of synthesized nanoparticles solution was added to both the dyes, and the readings were taken respectively. This was kept for 24 hours for degradation. After 24 hours again, the readings were taken. This was repeated for the next 24 hours.

\subsection{Seed germination.}

Groundnut seeds were obtained from a local store, Balaji Colony, Tirupati. The groundnut seeds were surface sterilized in $0.1 \% \mathrm{HgCl}_{2}$ and washed twice with sterile distilled water before germination. 50 grams groundnut seeds were soaked in distilled water for $24 \mathrm{~h}$ in the dark were transferred to beakers containing moist filter paper and watered. The germinated groundnut seeds were supplemented with $500 \mu \mathrm{l}$ of biosynthesized Aa-AgNPs, to observe the concentration-dependent effect on the growth of the root and shoot lengths using a metric scale after the first day, second days and continued for a week.

\section{Results and Discussion}

\subsection{Biosynthesis of Aa-AgNP's.}

The current study was carried out using a simple, eco-friendly, plant-mediated green method for biosynthesis of Aa-AgNPs. There are several previous studies on green synthesis of AgNPs using aqueous extracts of a wide variety of plants. In most of the previous research, the biosynthesis of silver nanoparticles showed similar results. The rate of reaction was very fast in some cases and very slow. Also, it took several hours to complete the reduction process [33-34]. In these studies, Figure 1 showed the successfully biosynthesized Aa-AgNPs using aqueous leaf extract of Artemisia апnиa. The bio-reduction of silver nitrate solution by aqueous leaf extract of Artemisia annua to elemental silver to Aa-AgNPs was detected by complete color from colorless solution to dark brown colored colloidal solution of Aa-AgNPs. 


\subsection{UV-visible spectroscopy analysis of Aa-AgNPs.}

The visible spectrum of the solution recorded at different periods consisted of an increasingly intense absorption at $441 \mathrm{~nm}$. The UV-visible absorption spectrum of the biosynthesized Aa-AgNPs was detected at $441 \mathrm{~nm}$, due to its surface plasmon resonance (SPR) in the visible region (Fig.2). The control sample did not show any color and consequently did not peak in the visible region. Hence, it is concluded that the biosynthesized Aa-AgNPs were the same as the formerly reported data by different scientists on silver nanoparticles [35-38].

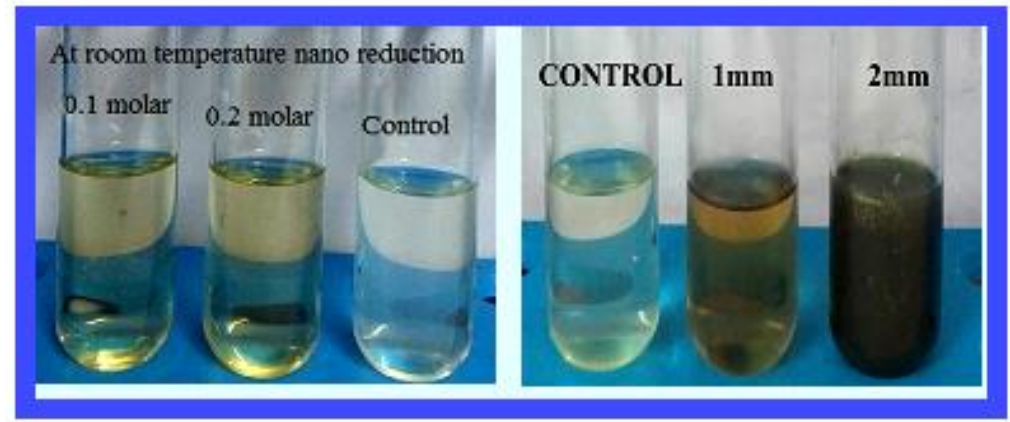

Figure 1. Aqueous leaf extract of Artemisia апnиa at room temperature and incubated at $70^{\circ} \mathrm{C}$ for color change.

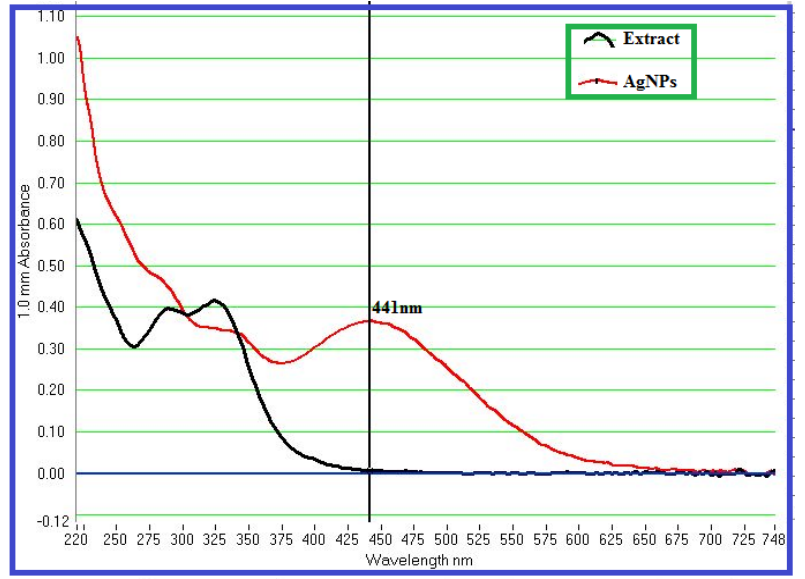

Figure 2. UV-Visble spectra of Artemisia annua leaf extract and biosynthesized Aa-AgNPs with 0.2(mM) silver nitrate.

\subsection{FTIR analysis of Aa-AgNPs.}

FTIR analysis was done to reveal the biomolecules responsible for the bioreduction of silver ions $\left(\mathrm{Ag}^{+}\right)$into $\mathrm{Aa}-\mathrm{AgNPs}\left(\mathrm{Ag}^{0}\right)$ and capping of Aa-AgNPs were biosynthesized. FTIR spectrum (Fig. 3a, 3b) showed the peaks at 3277, 2929, 1605, 1338, 1028 and $518 \mathrm{~cm}^{-1}$. The peak at $1028 \mathrm{~cm}-1$ responsible for the phenolic O-H group, and the peak at $1605 \mathrm{~cm}^{-1}$ could be assigned to aromatic $\mathrm{C}=\mathrm{C}$ stretching vibrations. Hence, these two peaks confirmed the involvement of flavonoids or polyphenolic compounds in silver nitrate bioreduction into AaAgNPs. The proteins also played an important role in the capping, and stabilization of AaAgNPs was confirmed by peaks $3277 \mathrm{~cm}^{-1}$ and $2929 \mathrm{~cm}^{-1}$. The peak at $3277 \mathrm{~cm}^{-1}$ was responsible for N-H stretching of the secondary amide of the proteins. The peak at $2929 \mathrm{~cm}-1$ could correspond to $\mathrm{C}-\mathrm{H}$ stretching of the methylene group of proteins. The peak at $1338 \mathrm{~cm}-$ 1 could be assigned to vibrations of $\mathrm{C}-\mathrm{N}$ stretchings belongs to aromatic amines. FTIR spectra measurements revealed that the proteins possess a strong affinity to bind with metal and could be involved in the stabilization of the AgNPs synthesized by Artemisia annua leaf extract, which were similar to the previous analysis by various researchers [39-41]. 

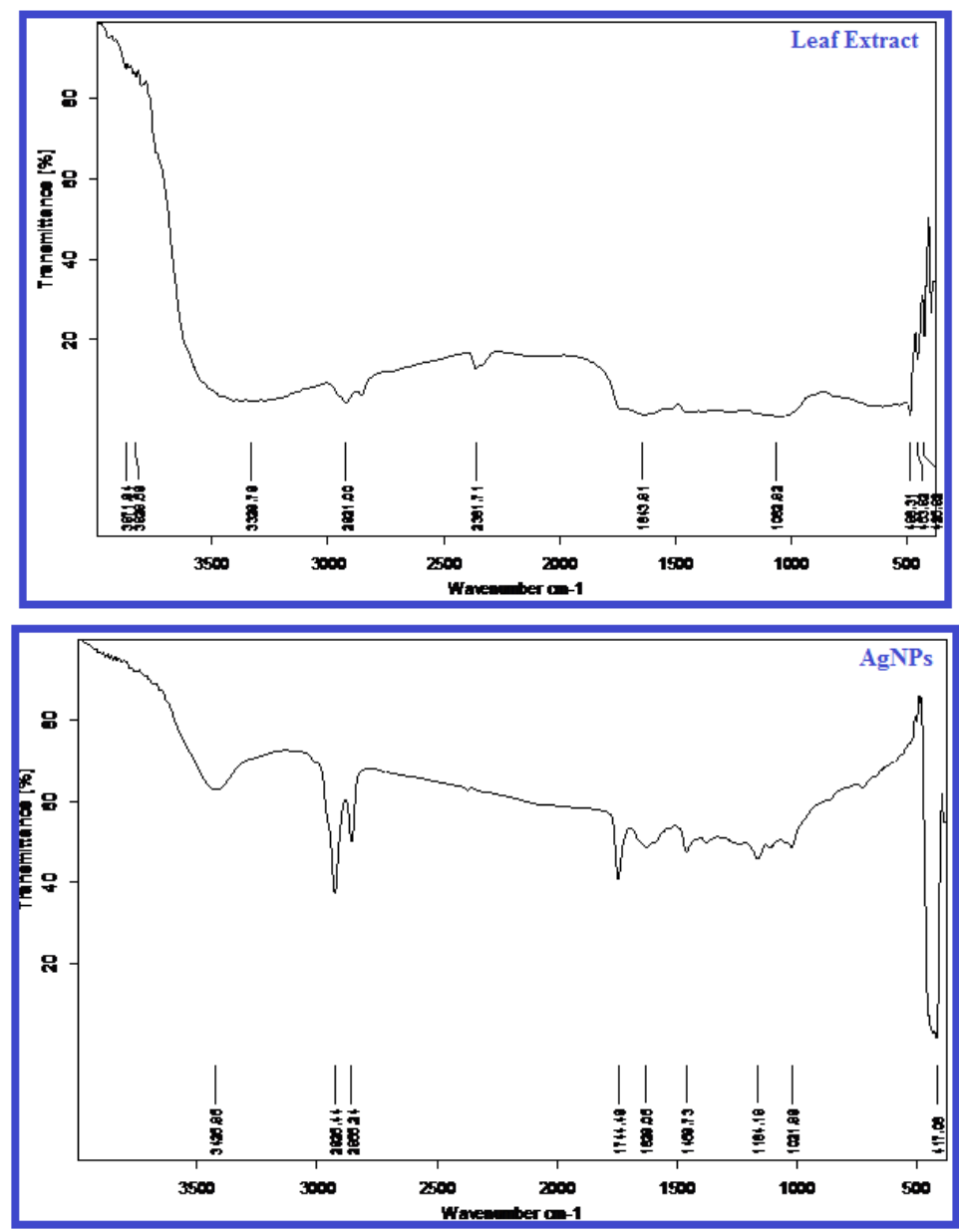

Figure 3. FTIR analysis (a) FTIR spectra of leaf extract (b) FTIR spectra of Aa- AgNPs synthesized.

\subsection{Particle size and Zeta potential analysis of Aa-AgNPs.}

Dynamic light scattering technique was used to measure the particle size and zeta potential value of the biosynthesized Aa-AgNPs. The stability of biosynthesized AgNPs depends on both size and surface charge (zeta potential value) present on the AgNPs. The data obtained from DLS measurements revealed that the particle size of AgNPs was 1-5 nm (Fig. 4), with an average size of hydrodynamic radii of $1.9 \mathrm{~nm}$. The zeta potential value of the AaAgNPs was detected to be $-26.1 \mathrm{mV}$ (Fig. 5), which is similar to previous reports [35-37]. The high negative value of AgNPs supports their good colloidal nature, high dispersity, and longterm stability due to negative-negative repulsion.

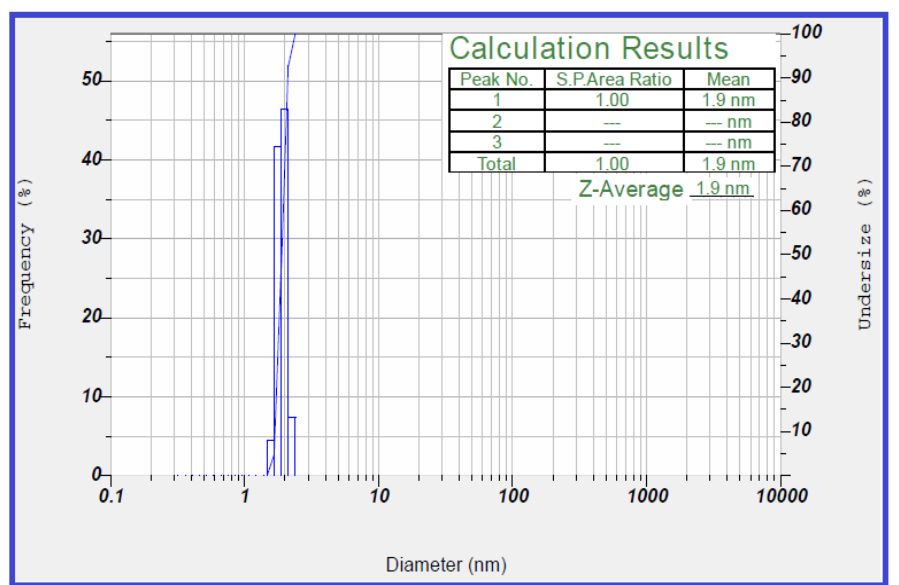

Figure 4. Particle size distribution curve of Aa- AgNPs synthesized from Artemisia annua leaf extract. 


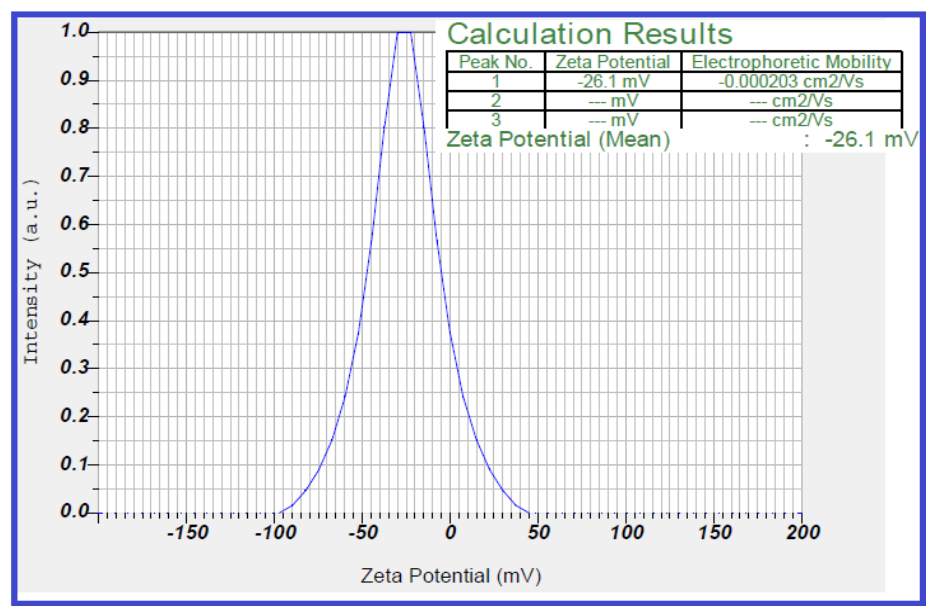

Figure 5. Zeta potential analysis of biosynthesized Aa-AgNPs.

\subsection{DPPH free-radical scavenging assay of Aa-AgNPs.}

In the present study, the antioxidant activity of the green synthesized Aa-AgNPs was checked by DPPH free radical scavenging assay. This method is dependent on the reduction of DPPH radical to the non-radical form of $\mathrm{DPPH}-\mathrm{H}$ in the presence of a hydrogen-donating antioxidant. The radical scavenging activity (RSA) values of A-AgNPs and standard ascorbic acid were represented (Fig. 6). The RSA of the Aa-AgNPs was increased with the increasing concentration. The maximum RSA was detected at the highest test concentration of $500 \mu \mathrm{g} / \mathrm{ml}$ used in this assay and was found to be $84.99 \%$.

In contrast, the RSA value of the aqueous leaf extract of Artemisia annua was detected to be $73.04 \%$ at the same concentration. Generally, the plants are usually rich in polyphenols and other secondary metabolites. The Artemisia annua plant has artemisinin, a sesquiterpene that contains various biomedical and pharmaceutical functions. Thus, the plant secondary metabolites components give up hydrogen atoms from their hydroxyl groups to free radicals and form stable phenoxyl radicals. The results revealed that the Aa-AgNPs have excellent antioxidant activity. The earlier report on plant-humic acids and other plant-mediated silver nanoparticles also have proven to show the excellent antioxidant activity [35-39,42]. DPPH stable free radical method is an easy, rapid, and sensitive way to survey a specific compound or plant extracts' antioxidant activity.

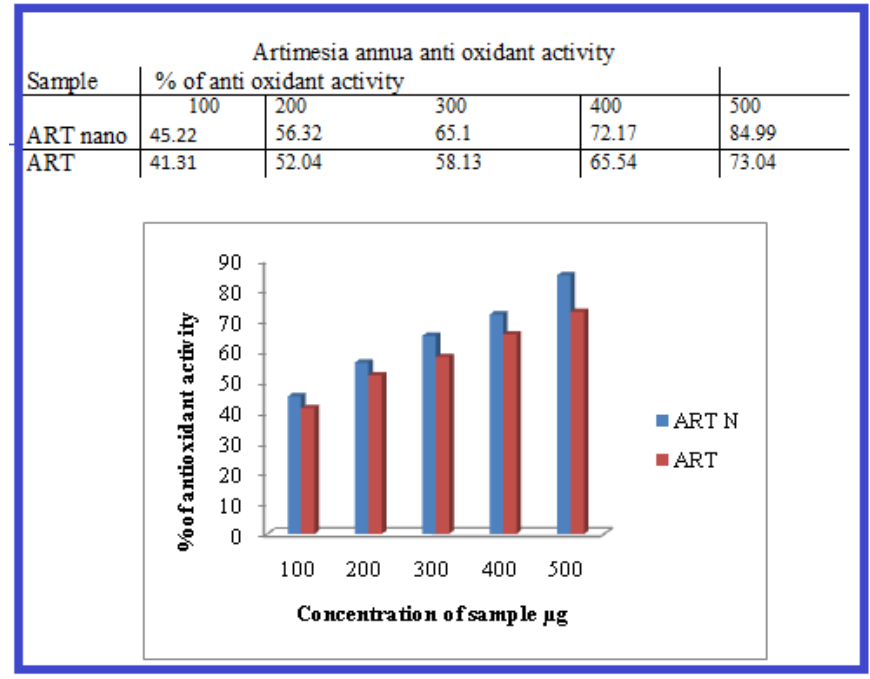

Figure 6. Antioxidant activity of biosynthesized Aa-AgNPs by DPPH method. 


\subsection{Antibacterial activity of Aa-AgNPs.}

There are several previous reports on antimicrobial activity using biosynthesized silver nanoparticles on different Gram-negative and Gram-positive bacterial strains [14-18]. The present study of various concentrations of green Aa-AgNPs was studied against four different microbial species [Escherichia coli, Bacillus subtilis, Staphylococcus aureus, and Klebsiella pneumoniae]. The biosynthesized Aa-AgNPs showed good inhibitory activity against both Gram +ve and Gram -ve bacteria at different concentrations. The zone of inhibition (ZOI) was observed in all bacterial species. The antibacterial studies using leaf extract of Artemisia апnиа was also studied in different concentrations (10,20,30, $50 \mathrm{ug} / \mathrm{mL})$ against E.coli, B.subtilis, S.aureous, K. pneumoniae. The Artemisia annua extract showed various antibacterial activity ranges, and the Aa-AgNPs exhibited moderate antibacterial activity compared with that of levofloxacin (Fig. 7; Table. 1). The results were similar to the earlier reports $(19-20 \& 37,42)$

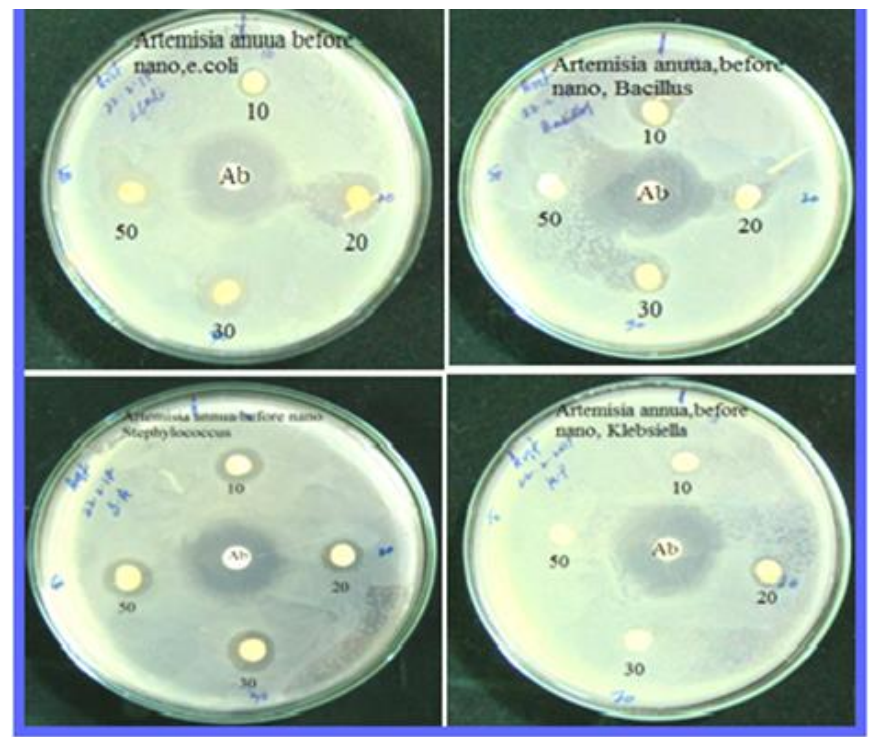

Figure 7. Antimicrobial activity of biosynthesized Aa-AgNPs against bacteria E.coli, B.subtilis, S.aureous, K. pneumonia.

Table 1. Antibacterial activity of Artemisia annua Leaf extract and Aa-AgNPS.

\begin{tabular}{l|l|l|l|l|l|l|l|l|l} 
& \multicolumn{2}{|l|}{ Leaf extract of Artemisia аппиа $\mathrm{L}(\mathrm{ZOI}$ in $\mathrm{mm})$} & \multicolumn{3}{l}{ Aa-AgNPs $(\mathrm{ZOI}$ in mm $)$} \\
\hline Concentration & $10 \mathrm{mcg}$ & $20 \mathrm{mcg}$ & $30 \mathrm{mcg}$ & $50 \mathrm{mcg}$ & Antibiotic 5mcg & $10 \mathrm{mcg}$ & $20 \mathrm{mcg}$ & $30 \mathrm{mcg}$ & $50 \mathrm{mcg}$ \\
\hline E.coli & 0.35 & 0.5 & 0.6 & 0.75 & 30 & 0.65 & 0.75 & 0.9 & 0.65 \\
\hline Bacillus & 0.5 & 0.5 & 0.5 & 0.75 & 30 & 0.7 & 0.75 & 0.9 & 0.65 \\
\hline Staphylococcus & 0.5 & 0.7 & 0.5 & 0.2 & 28 & 0.75 & 0.75 & 0.95 & 0.85 \\
\hline Klebsiella & 0.5 & 0.6 & 0.5 & 0.75 & 25 & 0.65 & 0.85 & 0.85 & 0.8
\end{tabular}

3.7. Degradation of dyes studies of Aa-AgNPs.

The photocatalytic activity of Aa-AgNPs on the degradation of food dyes was confirmed with the dyes lemon yellow and orange-red. The biosynthesized Aa-AgNPs exhibited very good dye degradation activity (Fig. 8). Previous studies were conducted on dye degradation of textile dyes and indicator colors. We are first to demonstrate catalytic activity using food dyes. 


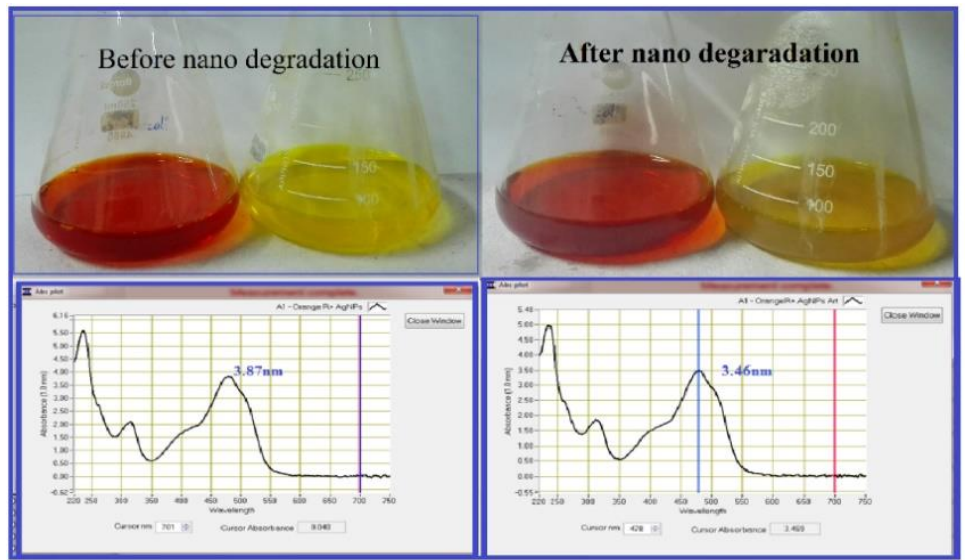

Figure 8. Light yellow color of the reaction solution containing. $1 \mathrm{mM} \mathrm{AgNO}_{3}$ and (c) $0.2 \mathrm{mM} \mathrm{AgNO}_{3}$ color change of the reaction solution from light yellow to dark brown, indicating dye degradation.

\subsection{Effect of Aa-AgNPs on seed germination.}

The effect of silver nanoparticles on seed germination is evaluated by comparing the germination percentage by taking two groups of groundnut seeds and adding silver nanoparticles to one group and taking control as another group. We observed differences in seedlings' growth in both silver nanoparticles treated and control (Fig. 9). The growth of seeds with silver nanoparticles is different from the growth of seeds in control. Thus it is concluded that the effect of Aa-AgNPs on seed germination is very promising. Seedlings count decreases in nano treated seeds than compared to control. In control, the germination percentage is $25 \%$, and in Aa-AgNPs treated germination percentage is $43 \%$.

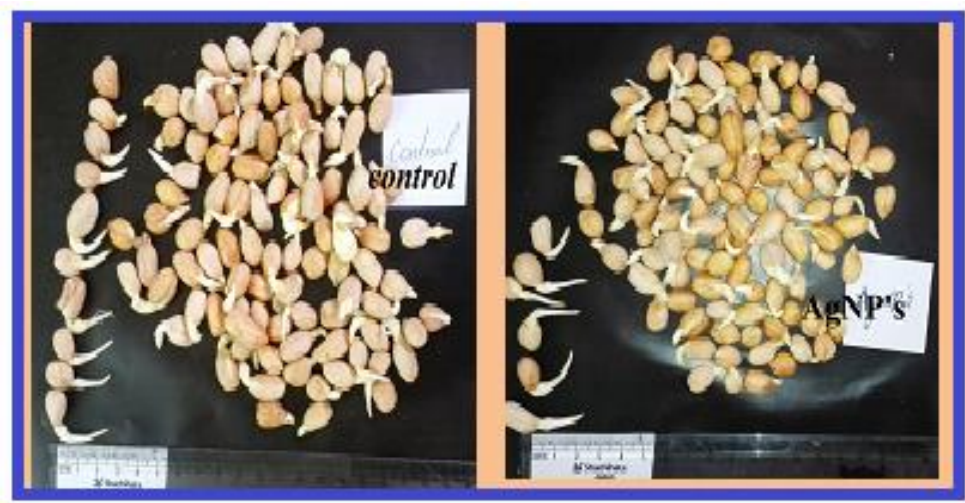

Figure 9. Effect of biosynthesized Aa-AgNPs on Seed germination.

\section{Conclusions}

In this work, a stable and straightforward process has been adopted to the biosynthesis of stable Aa-AgNPs. The developed method is inexpensive and useful to generate vast quantities of long-standing, even Aa-AgNPs. The initial reaction of bioreduction was the colorless solution. The complete reduction took place in 12 hours. The reaction turned from colorless to light brown, and the SPR band was dectected at $441 \mathrm{~nm}$, indicating silver nanoparticle formation. The spectral characterization of the biosynthesized Aa-AgNPs was carried-out by various spectroscopy methods. The biosynthesized Aa-AgNPs were very small in size between $1 \mathrm{~nm}$ to $5 \mathrm{~nm}$, with an average of $1.9 \mathrm{~nm}$. The biosynthesized Aa-AgNPs leaf extract of Artemisia annиa has revealed excellent free radical scavenging activity and rational 
antibacterial activity against both Gram -ve and Gram +ve bacteria strains when compared with standard antibiotics. The biosynthesized Aa-AgNPs also showed an encouraging and prospective effect on seed germination. They also exhibited excellent photocatalytic activity against lemon yellow and orange-red food dyes.

\section{Funding}

No external funding was received for this research work.

\section{Acknowledgments}

The authors are grateful to DST PURSE Center, Sri Venkateswara University, Tirupati, and DST CURIE, Sri Padmavati Mahila Visvavidyalayam (Women's University), Tirupati for providing facility to carry out present research work.

\section{Conflicts of Interest}

No conflict of interest.

\section{References}

1. Sharma,V.K.; Yngard, R.A.; Lin, Y. Silver nanoparticles: Green synthesis and their antimicrobial activities. Advances in Colloid and Interface Science 2009, 145, 83-96, https://doi.org/10.1016/j.cis.2008.09.002.

2. Gopinath V.; Mubarak A. D.; Priyadarshini S.; Prishadharsshini N.M.; Thajuddin N.; Velusamy P. Biosynthesis of silver nanoparticles from Tribulus terrestris and its antimicrobial activity: a novel biological approach. Colloids Surf B Biointerfaces 2012 96: 69-74, https://doi.org/10.1016/j.colsurfb.2012.03.023.

3. Adams F. C., Barbante C. Nanoscience, nanotechnology and spectrometry. Spectrochim Acta Part B Atspectrosc 2013 86: 3-13, https://doi.org/10.1016/j.sab.2013.04.008.

4. Gurunathan, S.; Lee, K.J.; Kalishwaralal, K.; Sheikpranbabu, S.; Vaidyanathan, R.; Eom, S.H. Antiangiogenic properties of silver nanoparticles. Biomaterials 2009, 30, 6341-6350, https://doi.org/10.1016/j.biomaterials.2009.08.008.

5. Oei, J.D.; Zhao, W.W.; Chu, L.; DeSilva, M.N.; Ghimire, A.; Rawls, H.R.; Whang, K. Antimicrobial acrylic materials with in situ generated silver nanoparticles. Journal of Biomedical Materials Research Part B: Applied Biomaterials 2012, 100B, 409-415, https://doi.org/10.1002/jbm.b.31963.

6. Ezzatzadeh, E.; Farjam, M.H.; Rustaiyan, A. Comparative evaluation of antioxidant and antimicrobial activity of crude extract and secondary metabolites isolated from Artemisia kulbadica. Asian Pacific Journal of Tropical Disease 2012, 2, S431-S434, https://doi.org/10.1016/S2222-1808(12)60198-4.

7. Tao, A.; Sinsermsuksakul, P.; Yang, P. Polyhedral Silver Nanocrystals with Distinct Scattering Signatures. Angewandte Chemie International Edition 2006, 45, 4597-4601, https://doi.org/10.1002/anie.200601277.

8. Mallick, K.; Witcomb, M.J.; Scurrell, M.S. Self-assembly of silver nanoparticles in a polymer solvent: formation of a nanochain through nanoscale soldering. Materials Chemistry and Physics 2005, 90, 221-224, https://doi.org/10.1016/j.matchemphys.2004.10.030.

9. Li, K.; Zhang, F.-S. A novel approach for preparing silver nanoparticles under electron beam irradiation. Journal of Nanoparticle Research 2010, 12, 1423-1428, https://doi.org/10.1007/s11051-009-9690-2.

10. Le, A.T.; Tam, L.T.; Tam, P.D.; Huy, P.T.; Huy, T.Q.; Van Hieu, N.; Kudrinskiy, A.A.; Krutyakov, Y.A. Synthesis of oleic acid-stabilized silver nanoparticles and analysis of their antibacterial activity. Materials Science and Engineering: C 2010, 30, 910-916, https://doi.org/10.1016/j.msec.2010.04.009.

11. Nadagouda, M.N.; Speth, T.F.; Varma, R.S. Microwave-assisted green synthesis of silver nanostructures. Acc Chem Res. 2011, 44, 469-478, https://doi.org/10.1021/ar1001457.

12. Zamiri, R.; Zakaria, A.; Abbastabar, H.; Darroudi, M.; Husin, M.S.; Mahdi, M.A. Laser-fabricated cost or oil-capped silver nanoparticles. Int J Nanomedicine 2011,6, 565-568, https://doi.org/10.2147/IJN.S16384.

13. Kotakadi, V.S.; Gaddam, S.A.; Subba Rao, Y.; Prasad, T.N.V.K.V.; Varada Reddy, A.; Sai Gopal, D.V.R. Biofabrication of silver nanoparticles using Andrographis paniculata. European Journal of Medicinal Chemistry 2014, 73, 135-140, https://doi.org/10.1016/j.ejmech.2013.12.004.

14. Kotakadi, V.S.; Rao, Y.S.; Gaddam, S.A.; Prasad, T.N.V.K.V.; Reddy, A.V.; Gopal, D.V.R.S. Simple and rapid biosynthesis of stable silver nanoparticles using dried leaves of Catharanthus roseus. Linn. G. Donn and its anti microbial activity. Colloids and Surfaces B: Biointerfaces 2013, 105, 194-198, https://doi.org/10.1016/j.colsurfb.2013.01.003. 
15. Venkata Subbaiah, K.; Susmila Aparna, G.; Sucharitha, K.V.; Prasad, T.N.V.K.V.; Gopal, D.V.R.S. Ficus Fruit-mediated Biosynthesis of Silver Nanoparticles and their Antibacterial Activity Against Antibiotic Resistant E. coli Strains. Current Nanoscience 2015, 11, 527-538, http://dx.doi.org/10.2174/1573413711666150126225951.

16. Kotakadi, V.S.; Gaddam, S.A.; Venkata, S.K.; Sai Gopal, D.V.R. New generation of bactericidal silver nanoparticles against different antibiotic resistant Escherichia coli strains. Applied Nanoscience 2015, 5, 847-855, https://doi.org/10.1007/s13204-014-0381-7.

17. Kotakadi, V.S.; Gaddam, S.A.; Venkata, S.K.; Sarma, P.V.G.K.; Sai Gopal, D.V.R. Biofabrication and spectral characterization of silver nanoparticles and their cytotoxic studies on human CD34 +ve stem cells. 3 Biotech 2016, 6, 216- 221, https://doi.org/10.1007/s13205-016-0532-5.

18. Gaddam, S.A.; Kotakadi, V.S.; Sai Gopal, D.V.R.; Subba Rao, Y.; Varada Reddy, A. Efficient and robust biofabrication of silver nanoparticles by cassia alata leaf extract and their antimicrobial activity. Journal of Nanostructure in Chemistry 2014, 4, 82-88, https://doi.org/10.1007/s40097-014-0082-5.

19. Pathak, J.; Sonker, A.S.; Singh, R.V.; Kumar, D.; Sinha, R.P. Synthesis of silver nanoparticles from extracts of Scytonema geitleri HKAR-12 and their in vitro antibacterial and antitumor potentials. Letters in Applied NanoBioScience 2019, 8, 576-585, https://doi.org/10.33263/LIANBS83.576585.

20. Murugan, N.; Natarajan, D. Bionanomedicine for antimicrobial therapy - a case study from Glycosmis pentaphylla plant mediated silver nanoparticles for control of multidrug resistant bacteria. Letters in Applied NanoBioScience 2016, 8, 523-540.

21. Khosravi-Darani, K.; da Cruz, A.G.; Mozafari, M.R.; Abdi, Z.; Ahmadi, N. Biosynthesis of metal nanoparticles by probiotic bacteria. Letters in Applied NanoBioScience 2019, 8, 619-626, https://doi.org/10.33263/LIANBS83.619626.

22. Khosravi-Darani, K.; da Cruz, A.G.; Shamloo, E.; Abdimoghaddam, Z.; Mozafari, M.R. Green synthesis of metallic nanoparticles using algae and microalgae. Letters in Applied NanoBioScience 2019, 8, 666-670, https://doi.org/10.33263/LIANBS83.666670.

23. Mojarrab, M.; Delazar, A.; Esnaashari, S.; Afshar, F.H. Chemical composition and general toxicity of essential oils extracted from the aerial parts of Artemisia armeniaca Lam. and A. incana (L.) Druce growing in Iran. Research in pharmaceutical sciences 2013, 8, 65-69.

24. Bora, K.S.; Sharma, A. The Genus Artemisia: A Comprehensive Review. Pharmaceutical Biology 2011, 49 , 101-109, https://doi.org/10.3109/13880209.2010.497815.

25. Gilani, A.H.; Yaeesh, S.; Jamal, Q.; Ghayur, M.N. Hepatoprotective activity of aqueous-methanol extract of Artemisia vulgaris. Phytotherapy Research 2005, 19, 170-172, https://doi.org/10.1002/ptr.1632.

26. Abad, M.J.; Bedoya, L.M.; Apaza, L.; Bermejo, P. The Artemisia L. Genus: A Review of Bioactive Essential Oils. Molecules 2012, 17, 2542-2566, https://doi.org/10.3390/molecules17032542.

27. Aniya, Y.; Shimabukuro, M.; Shimoji, M.; Kohatsu, M.; Gyamfi, M.A.; Miyagi, C.; Kunii, D.; Takayama, F.; Egashira, T. Antioxidant and Hepatoprotective Actions of the Medicinal Herb Artemisia campestris from the Okinawa Islands. Biological \& Pharmaceutical Bulletin 2000, 23, 309-312, https://doi.org/10.1248/bpb.23.309.

28. Kordali, S.; Cakir, A.; Mavi, A.; Kilic, H.; Yildirim, A. Screening of Chemical Composition and Antifungal and Antioxidant Activities of the Essential Oils from Three Turkish Artemisia Species. J Agric Food Chem 2005, 53, 1408-1416, https://doi.org/10.1021/jf048429n.

29. Kordali, S.; Kotan, R.; Mavi, A.; Cakir, A.; Ala, A.; Yildirim, A. Determination of the Chemical Composition and Antioxidant Activity of the Essential Oil of Artemisia dracunculus and of the Antifungal and Antibacterial Activities of Turkish Artemisia absinthium, A. dracunculus, Artemisia santonicum, and Artemisia spicigera Essential Oils. J Agric Food Chem 2005, 53, 9452-9458, https://doi.org/10.1021/jf0516538.

30. Romero, M.R.; Serrano, M.A.; Vallejo, M.; Efferth, T.; Alvarez, M.; Marin, J.J.G. Antiviral Effect of Artemisinin from Artemisia annua against a Model Member of the Flaviviridae Family, the Bovine Viral Diarrhoea Virus (BVDV). Planta Med 2006, 72, 1169-1174, https://doi.org/10.1055/s-2006-947198.

31. Emami, S.A.; Aghazari, F.Les Phanerogames Endemiques de la Flore d'Iran. Publications de I'Universite de Teheran, Teheran. 2011.

32. Ghahreman, A.; Attar, F.Biodiversity of plant species in Iran. Tehran University Publication, Tehran. 1999.

33. Netala, V.R., Kotakadi, V.S., Domdi, L. et al. Biogenic silver nanoparticles: efficient and effective antifungal agents. Appl Nanosci 2016, 6, 475-484, https://doi.org/10.1007/s13204-015-0463-1.

34. Hutchison, J.E. Greener Nanoscience: A Proactive Approach to Advancing Applications and Reducing Implications of Nanotechnology. ACS Nano 2008, 2, 395-402, https://doi.org/10.1021/nn800131j.

35. Palle, S.R.; Penchalaneni, J.; Lavudi, K.; Gaddam, S.A.; Kotakadi, V.S.; Challagundala, V.N. Green Synthesis of Silver Nanoparticles by Leaf Extracts of Boerhavia erecta and Spectral Characterization and Their Antimicrobial, Antioxidant ad Cytotoxic Studies on Ovarian Cancer Cell Lines. Letters in Applied NanoBioScience 2020, 9, 1165-1176.

36. Netala, V.R.; Bukke, S.; Domdi, L.; Soneya, S.; G. Reddy, S.; Bethu, M.S.; Kotakdi, V.S.; Saritha, K.V.; Tartte, V. Biogenesis of silver nanoparticles using leaf extract of Indigofera hirsuta L. and their potential 
biomedical applications (3-in-1 system). Artificial Cells, Nanomedicine, and Biotechnology 2018, 46, 11381148, https://doi.org/10.1080/21691401.2018.1446967.

37. Kumaram, V.S.; Gaddam, S.; Kotakadi, V.S.; Gopal, D.V.R.S. Multifunctional Silver Nanoparticles by Fruit Extract of Terminalia belarica and their Therapeutic Applications: A 3-in-1 System. Nano Biomedicine and Engineering 2018, 10,279-274, https://doi.org/10.5101/nbe.v10i3.p279-294.

38. Netala, V.R.; Kotakadi, V.S.; Nagam, V.; Bobbu, P.; Ghosh, S.B.; Tartte, V. First report of biomimetic synthesis of silver nanoparticles using aqueous callus extract of Centella asiatica and their antimicrobial activity. Applied Nanoscience 2015, 5, 801-807, https://doi.org/10.1007/s13204-014-0374-6.

39. Litvin, V.A.; Galagan, R.L.; Minaev, B.F. Kinetic and mechanism formation of silver nanoparticles coated by synthetic humic substances. Colloids and Surfaces A: Physicochemical and Engineering Aspects 2012, 414, 234-243, https://doi.org/10.1016/j.colsurfa.2012.08.036.

40. Litvin, V.A.; Minaev, B.F. Spectroscopy study of silver nanoparticles fabrication using synthetic humic substances and their antimicrobial activity. Spectrochimica Acta Part A: Molecular and Biomolecular Spectroscopy 2013, 108, 115-122, https://doi.org/10.1016/j.saa.2013.01.049.

41. Palithya, S.; Kotakadi, V.S.; Pechalaneni, J.; Challagundla, V.N. Biofabrication of Silver nanoparticles by leaf extract of Andrographis serpyllifolia and their antimicrobial and antioxidant activity. International Journal of Nano Dimension 2018, 9, 398-407.

42. Kumari, R.; Mishra, R.C.; Yadav, J.P. Antioxidant and cytotoxic studies of Acacia nilotica twig extract and their green synthesized silver nanoparticles. Letters in Applied NanoBioScience 2020, 9, 975-980, https://doi.org/10.33263/LIANBS92.975980. 